\title{
GEOGRAFIA A SERVIÇO DA EMERGÊNCIA EM SAÚDE PÚBLICA
}

\author{
Raul Borges Guimarães
} Professor titular do Departamento de Geografia da Faculdade e Ciências e Tecnologia da Unesp. https: //orcid.org /0000-0002-9925-5374 raul.guimaraes@unesp.br

Rafael de Castro Catão Professor adjunto do Departamento de Geografia da Universidade Federal do Espírito Santo. https: //orcid.org /0000-0003-2837-0364 rafael.catao@ufes.br

Paulo Nuno Nossa Professor Auxiliar do Departamento de Geografia e Turismo da Universidade de Coimbra, Portugal. https: //orcid.org/0000-0001-5000-8754 paulonnossa@gmail.com

É com satisfação que trazemos a público esta edição especial da Revista Brasileira de Geografia Médica e da Saúde - Hygeia, que reúne a contribuição de geógrafas e geógrafos da saúde, e pesquisadores de áreas afins, que responderam rapidamente à chamada para a publicação de resultados de pesquisa acerca da pandemia da COVID-19. O resultado foi surpreendente, demonstrando a importância do conhecimento geográfico nesse grande esforço coletivo de compreensão da situação de emergência em saúde pública que vive o Brasil e o mundo em 2020. São quarenta e cinco trabalhos selecionados de quatro países (Cuba, México e Portugal, além do Brasil), com trinta e quatro estudos de casos, quatro artigos de revisão, três relacionando políticas de saúde e outros três de cunho reflexivo, além de um estudo comparativo. Em relação aos temas, o processo de mapeamento e a análise da difusão espacial da COVID-19 foram os mais recorrentes, seguidos da discussão sobre os transportes e fluxos de pessoas, isolamento social e políticas de saúde, cobrindo ainda temas como vulnerabilidades, riscos diferenciados por raça/cor e uma análise do papel do poder público na vigilância e monitoramento da disseminação da doença.

Para apresentar esse conjunto de textos, fizemos dois tipos de análise. O primeiro deles considerou a abrangência territorial dos trabalhos que tiveram o foco no Brasil. Conforme pode ser observado na representação cartográfica abaixo, dentre os 45 artigos do presente número especial, quatro são estudos na escala nacional, vinte tem uma abrangência regional e no nível local, cobrindo dezesseis Unidades da Federação do Brasil, com diversos recortes. Minas Gerais, Santa Catarina, Rio Grande do Sul e Amazonas foram os estados brasileiros mais analisados. Mas há também artigos que discutem a distribuição da COVID-19 em cidades distribuídas entre as cinco marco-regiões do país. Enfim, essa análise demonstra, claramente, que os artigos aqui reunidos proporcionam uma visão ampla e de conjunto do impacto da pandemia da COVID-19 em um país com as dimensões continentais e desigualdades regionais como o Brasil.

Outro tipo de análise foi dos autores mais citados nos artigos dessa edição especial da Hygeia. Para isso, além do número de vezes que os autores são citados, foi organizada uma matriz de relacionamentos entre as referências utilizadas e os artigos dessa edição especial. Dessa forma, foi possível realizar uma análise matricial dos autores citados, o que permite uma aproximação acerca dos marcos teóricos que foram considerados pela geografia da saúde para pensar a pandemia da COVID-19. Dentre os autores citados, Milton Santos é o mais influente, com 11 citações, com destaque para uma de suas principais obras - A natureza do espaço (1996), com 5 citações; mas também Por uma outra globalização (2000), com 3 citações. Em segundo lugar são mais citados Raul Borges Guimarães, principalmente Saúde: fundamentos de Geografia humana; e a tese de Rafael de Castro Catão. Em seguida, os autores de maior destaque são Roberto Lobato Corrêa e David Harvey, com seu capítulo Política anticapitalista em tempos de Covid-19, publicado esse ano. 


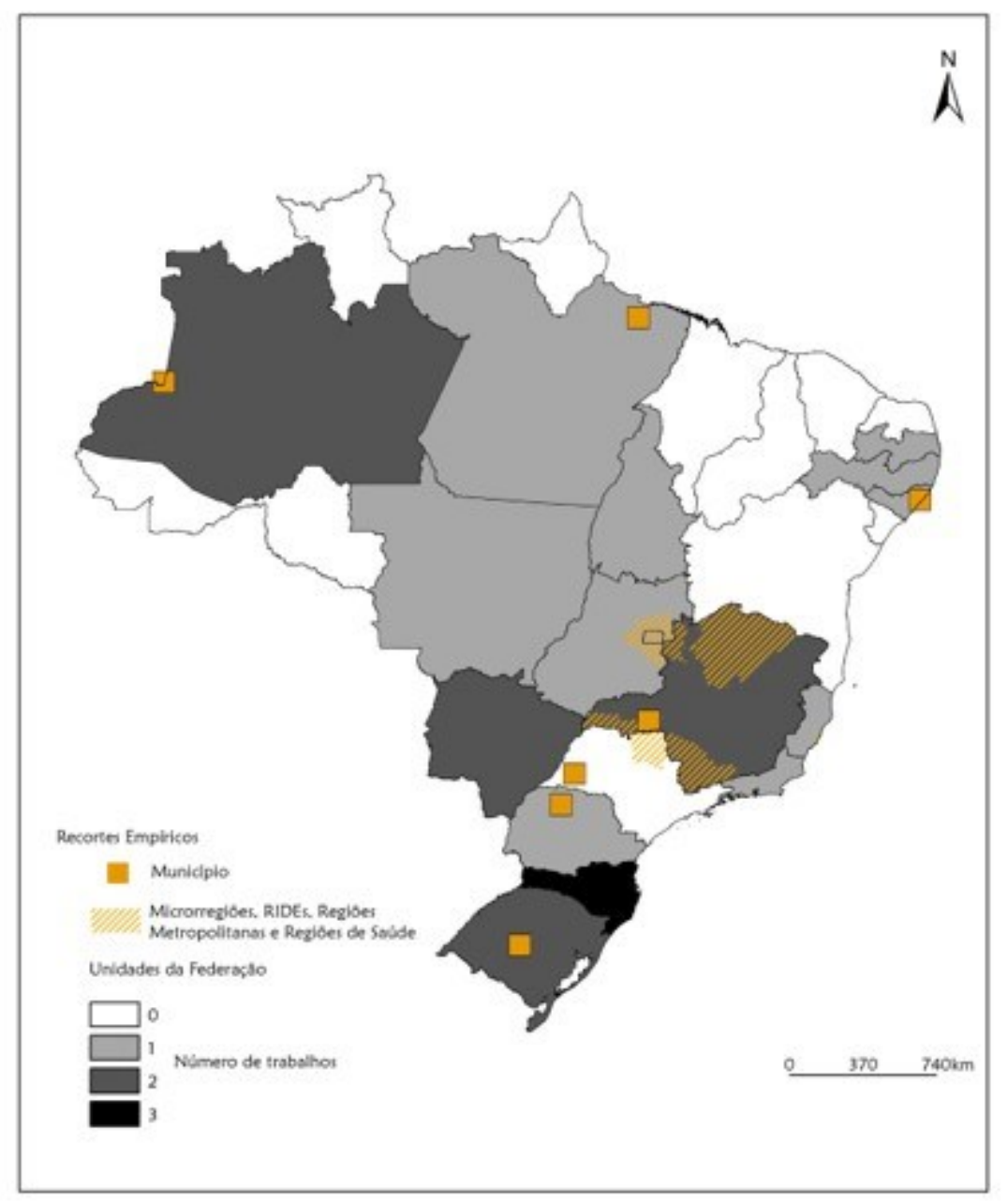

Organização e Elaboração: Carolina Russo Simon, 2020.

Quando a análise dessa matriz de relacionamentos se desloca do nome do autor para o título do trabalho citado, é possível identificar outras referências que ganham centralidade no conjunto dos textos publicados neste número especial. Esse é o caso do artigo "Por que a circulação de pessoas tem peso na difusão da pandemia", produzido por Maria Encarnação Beltrão Sposito e Raul Borges Guimarães 1 . Outro artigo de grande relevância foi "O avanço da Covid-19 e o isolamento social como estratégia para redução da vulnerabilidade", produzido por Heitor Soares de Farias²; e o artigo "Emergência do novo coronavírus (SARS-CoV-2) e o papel de uma vigilância nacional em saúde oportuna e efetiva", produzido por Raquel Martins Lana ${ }^{3}$, Flávio Codeço Coelho, Marcelo Ferreira da Costa Gomes, Oswaldo Gonçalves Cruz, Leonardo Soares Bastos, Daniel Antunes Maciel Villela e Cláudia Torres Codeço; assim como o artigo de Júlio Henrique Rosa Croda e Leila Posenato Garcia ${ }^{4}$.

\footnotetext{
1 SPOSITO, M. E. B.; GUIMARÃES, R. B. Por que a circulação de pessoas tem peso na difusão da pandemia. São Paulo: Unesp, 26 mar. 2020. Disponível em: <https://www2.unesp.br/portal\#!/noticia/35626/por-que-acirculacao-de-pessoas-tem-peso-na-difusao-da-pandemia>.

2 FARIAS, H. S. O avanço da Covid-19 e o isolamento social como estratégia para redução da vulnerabilidade. Espaço e Economia, v. 9, n. 17, 2020. Disponível em: Acesso em: 24 abr 2020. https://doi.org/10.4000/espacoeconomia.11357.

3 LANA, R. M. et al. Emergência do novo coronavírus (SARS-CoV-2) e o papel de uma vigilância nacional em saúde oportuna e efetiva. Cadernos de Saúde Pública, v. 36, p. e00019620, 2020. https://doi.org/10.1590/0102$\underline{311 \times 00019620}$

${ }^{4}$ CRODA J.H.R.; GARCIA L.P. Immediate Health Surveillance Response to COVID-19 Epidemic. Epidemiol. Serv. Saúde, Brasília.. Epub Mar 23, 2020. https://doi.org/10.5123/S1679-49742020000100021.
} 
Relação matricial de autores citados

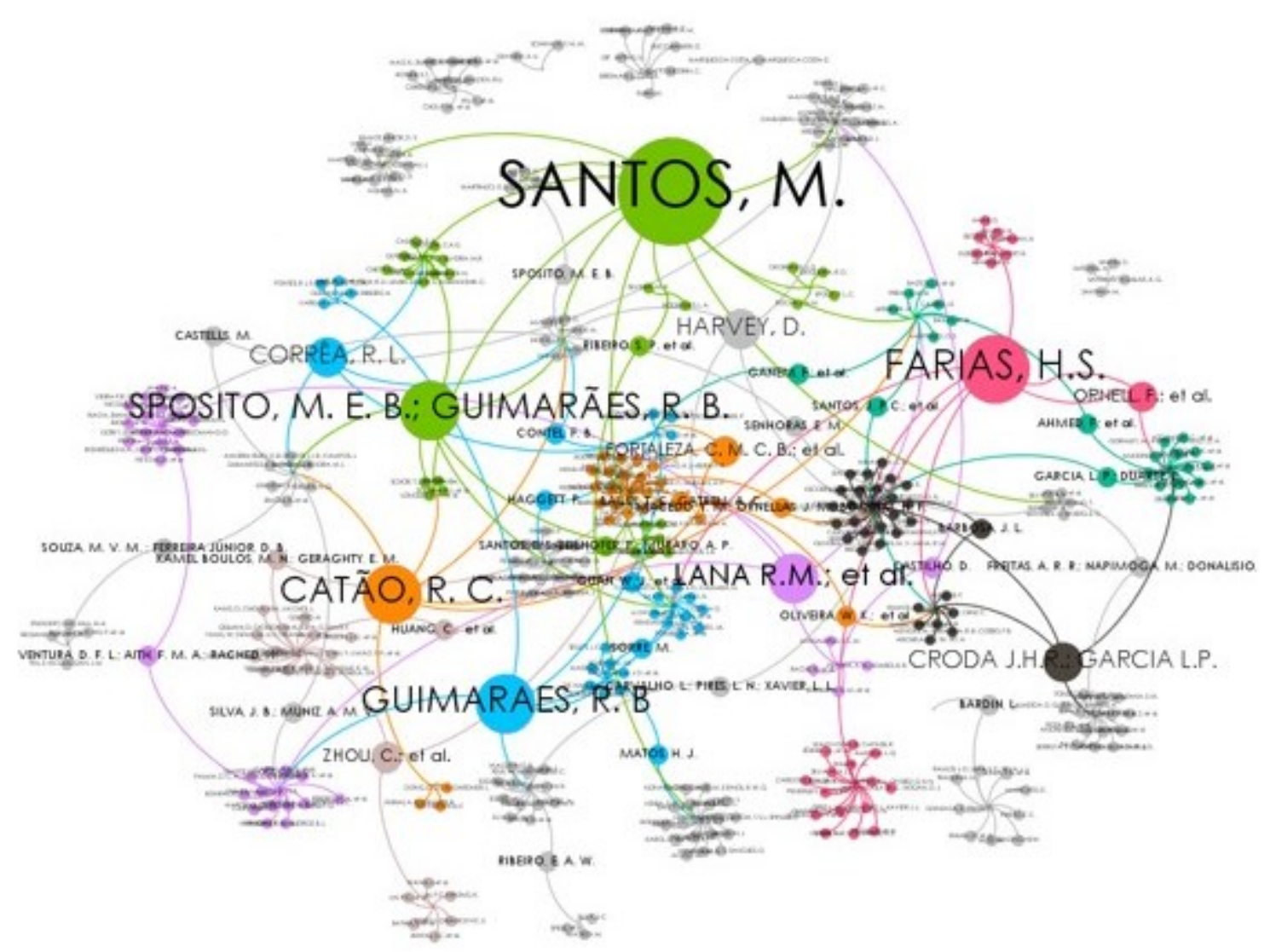

Organização e Elaboração: Carolina Russo Simon, 2020. 
Tanto o mapa da abrangência territorial dos artigos como as análise de matriz de relacionamentos das referências bibliográficas utilizadas nos artigos da presente edição especial demonstram grande capacidade dos pesquisadores da geografia da saúde e áreas afins para refletir sobre o novo coronavírus e seu impacto na saúde coletiva, considerando a capacidade de resposta dos serviços de saúde. Oficialmente, o primeiro caso confirmado no Brasil data do final de fevereiro de 2020, aportando na cidade de São Paulo proveniente do continente Europeu. Com inúmeras entradas em outras metrópoles brasileira, a doença segue o caminho da rede urbana, em direção às cidades menores e com menos infraestrutura de saúde. Na escala intraurbana, a difusão da doença segue das áreas de mais alto padrão se dirigindo para as periferias urbanas, encontrando contextos mais vulneráveis.

Os traços gerais da epidemia estão tornando-se mais definidos com o escrutínio de cientistas, de diversas áreas do conhecimento e, obviamente, o aspecto espacial constitui uma das questões principais. Compreender a difusão, o padrão espacial, os determinantes, contextos e vulnerabilidades, juntamente com a estruturação do sistema de saúde, as políticas de saúde territorializadas e as formas de combate constituem no métier consolidado da Geografia da Saúde. Adicionalmente, também se discute o contexto geopolítico desta pandemia, através do papel que o(s) processos(s) de globalização detiveram na propagação do vírus, desde a velocidade de propagação ampliada pela hiperconexão global em que vivemos desde o início do século $\mathrm{XXI}$, associada à deslocação de pessoas e bens, até às práticas de prevenção e contenção fortemente dependentes da repartição da produção de bens de proteção individual regionalmente concentrados. Outros temas mais recentes, como o isolamento social e a saúde mental, bem como a precariedade das nossas cidades iniciam aqui uma discussão que, seguramente se prolongará no tempo, à medida que os efeitos secundários, diretos e indiretos desta pandemia forem investigados.

Algumas perguntas vão sendo respondidas ao passo que outras darão, seguramente, motivos para novas iniciativas: apoiarão as nações a construção de um conhecimento partilhado e escrutinado por pares? Que resposta social e sanitária pode ou deve ser desenhada à medida que outros surtos, deste ou de outros "novos vírus" atingirem populações humanas à escala global? Será que o modelo de resposta organizado pelos Estados, orientado para a proteção individual ou focado na imunidade de grupo, terá algum nível de sancionamento social e político? Certamente, os artigos aqui reunidos vieram para enriquecer esse debate. Boa leitura! 